\title{
FIGURACIONES SIMBÓLICAS DE LA SERPIENTE EN EL MESTER DE CLERECÍA
}

\author{
ALICIA RAMADORI \\ Centro de Estudios Medievales y Literatura Comparada \\ Universidad Nacional del Sur (Argentina)
}

\begin{abstract}
Seguir las huellas de la serpiente a través de sus representaciones y simbologías en el mester de clerecía nos introduce en un universo textual regido por la variedad y la homogeneidad. La aparente paradoja se percibe ya desde la primera lectura de estas obras en lengua romance que conforman un género literario (Nicasio Salvador Miguel), una modalidad discursiva (Ángel Gómez Moreno) o una escuela poética (Isabel Uría Maqua), según nos inclinemos por adoptar alguna de las categorizaciones propuestas por los estudiosos del mester de clerecía. ${ }^{1}$ Su diversidad está dada por la materia tratada, que puede ser clásica, religiosa, histórico-nacional; por los géneros que confluyen en su composición: épica, hagiografía, milagro, roman; por los modelos propuestos: héroe guerrero, sabio, santo, caballero cortesano. Su homogeneidad se alcanza con la utilización exclusiva de un mismo patrón métrico, la conocida "cuaderna vía", la común presencia de procedimientos retóricos y discursivos, así como de
\end{abstract}

1 Cfr. Nicasio Salvador Miguel, "Mester de clerecía, marbete caracterizador de un género literario", Revista de Literatura, XLII, No 82 (1979), pp. 5-30. Carlos Alvar y Ángel Gómez Moreno, La poesía épica y de clerecía medievales, en Historia crítica de la Literatura Hispánica, II, Madrid, Taurus, 1988. Isabel Uría Maqua, Panorama crítico del «mester de clerecía», Madrid, Castalia, 2000. 
una intencionalidad didáctico-moralizante y una ideología semejantes. De este modo, el mester de clerecía responde a una misma concepción literaria y a una análoga formación intelectual de sus creadores quienes encarnan nuevos ideales espirituales, regidos por principios laicos y racionalistas, que surgen del proceso de renovación cultural que hizo eclosión en España en el siglo XIII y tuvo como genuinos representantes a los clérigos formados en las Universidades, especialmente en la de Palencia a comienzos de la centuria. ${ }^{2}$

En esta "diversa homogeneidad" estética, ideológica, creadora del mester de clerecía reside la conveniencia y adecuación de este conjunto textual para el estudio de los modos representativos, las funciones y simbolismos de los animales, precisamente, porque permiten comprobar la variedad dentro de la unidad. ${ }^{3}$ Para ello, en esta ocasión, nos centraremos en la figura de la serpiente y seguiremos su rastro simbólico en el Libro de Alexandre, en los Milagros de Nuestra Señora y tres poemas hagiográficos de Gonzalo de Berceo (San Millán, Santo Domingo y Santa Oria) y en el Poema de Fernán González. ${ }^{4}$

\section{LIBRO DE ALEXANDRE}

En el Libro de Alexandre, el elevado número y la variedad de animales figurados desarrollan un amplio espectro que abarca diferentes niveles de representación: ya sea que se refieran a la realidad material, conocida, que será sometida al poder de Alexandre; ya sea que se vinculen con el mundo de lo prodigioso y extraño, propio del espacio de los confines, nuevo orbe que Alexandre aspira conquistar y dominar.

La serpiente interviene en la conformación de imágenes, símiles y símbolos. Al momento de establecer analogías, se privilegia la condición innata del animal, especialmente las características naturales de ferocidad y bravura. En consecuencia, en los episodios que tienen que ver con el tema de la guerra,

\footnotetext{
2 Cfr. C. Alvar y Á. Gómez Redondo, op. cit. e I.Uría Maqua, op.cit.

${ }^{3}$ El estudio de los animales en el mester de clerecía ha sido el tema personal que he desarrollado en un proyecto de investigación "Didactismo y sátira en la literatura española medieval: función y simbolismo de los animales" (2003-2005), dirigido por Dra. Graciela Rossaroli y financiado por la Universidad Nacional. En el marco de este proyecto he publicado varios artículos y presentado ponencias en congresos de la especialidad.

${ }^{4}$ Se han utilizado las siguientes ediciones de los textos que se citan directamente en el trabajo: Libro de Alexandre, ed. J. Cañas Murillo, Madrid, Editora Nacional, 1978. Poema de Fernán González, Ed. A. Zamora Vicente, Madrid, Espasa-Calpe, Clásicos Castellanos, 1946. Gonzalo de Berceo, La vida de San Millán de la Cogolla, ed. crítica de B. Dutton, London, Tamesis, 1967. La vida de Santo Domingo de Silos, ed. T. Labarta de Chaves, Madrid, Castalia, 1972. Poema de Santa Oria, ed. I. Uría Maqua, Madrid, Castalia, 1981. Milagros de Nuestra Señora, ed. F. Baños, Barcelona, Crítica, 1997.
} 
aparecen los ejemplos más numerosos en los epítetos y símiles bélicos. Así se especifica que Eneas y Héctor andaban en el campo de batalla rabiosos como una sierpe fiera o brava (est. 549 y 552), o dos combatientes de nombre Nicanor se comportan "como sierpe raviosa" (est. 1383 y 2009). En otro pasaje, el persa Mega desafía a Clitus quien mató a sus dos hijos, apostrofándolo: “Ay, sierpe enconada, ¡mala passes la mar!” (1378b).

En el nivel discursivo, las imágenes de la serpiente cumplen una función que podríamos calificar como estética, especialmente en pasajes digresivos de carácter descriptivo. La figura del animal puede aparecer como ornamento de objetos suntuosos, por ejemplo, en la descripción del carro de Darío se detalla el trabajo artístico de la lazada del yugo conformada como una serpiente de oro:

Digámosvos del yugo, siquier de la laçada:

obra era greçisca nuevamente fallada, toda una serpiente la tenié embraçada, pero cadena era de oro muy delgada. (859).

En el catálogo del lapidario (est. 1468-1492), discurso de carácter simbólico que se incluye en el episodio de la descripción de Babilonia, se establecen referencias y comparaciones con animales. En el caso del azabache se correlacionan paralelamente sus efectos contra los demonios y las serpientes, a partir de la condición caliente de la piedra: "Allí son los gagates por natura ardientes, / que sacan los demonios, segudan las serpientes" (1470 ab). En este caso están presentes también las connotaciones negativas que la serpiente asume en su identificación con el diablo. Esta asociación simbólica se mantiene en el pasaje del descenso de doña Natura al Infierno en el que aparecen las serpientes en los umbrales infernales:

Silvan por las riberas muchas malas sirpientes, están días e noches aguzando los dientes, assechan a las almas, non tienen a al mientes, por esto peligraron los primeros parientes. (2341)

Otra asociación de la serpiente con el mundo del pecado y los vicios se manifiesta en una especie de fórmula con que el narrador y otros personajes exaltan el poder alcanzado por Alexandre: "homes, sierpes e bestias todo lo ha vençido" (Cfr. est. 2186, 2191, 2275, 2278, 2431, 2439). Esta expresión figurada adquiere un sentido moral particular en el poema porque sirve para significar el 
pecado de soberbia intelectual de Alexandre quien aspira al dominio total del Universo, violando los límites establecidos por la Naturaleza y permitidos por Dios y se convierte, por lo tanto, en causa última de la condena y muerte del protagonista.

Un ámbito propicio para las simbolizaciones se produce en la representación de los confines, hacia donde se dirige el ejército griego con el fin de extender su conquista por todo el orbe para someterlo al poder de Alexandre. Al internarse en tierras recónditas, se enfrentan con animales de enormes dimensiones y conductas insólitas. El espacio de los confines se caracteriza principalmente por ser un mundo desconocido y extraño, antes que por la irrupción del elemento maravilloso, sobrenatural. En este sentido, Jacques Le Goff destaca la interpretación de lo maravilloso cristiano que realizan algunos intelectuales medievales al presentar los mirabilia como fenómenos marginales, casos límite, excepcionales pero que se encuentran dentro del orden natural y son admitidos como verdaderos. ${ }^{5}$

Esta concepción del prodigio como lo ignoto y lo inexplorado permite sumar, a los propósitos conquistadores de la guerra, los fines cognitivos de una expedición científica. Complementariamente a esta función de configurar el prodigio, los animales constituyen obstáculos que se deben superar para alcanzar tales fines. En la superación de estas pruebas resultan indispensables los conocimientos eruditos y el ingenio de Alexandre que siempre encuentra la solución y la victoria sobre las dificultades naturales. Un ejemplo se presenta en el episodio de las serpientes, guardianas de la fuente, que impiden el acceso a los sedientos caballeros (2155-2163). Entonces Alexandre hace desnudar a sus hombres y evita así que sean atacados, apelando a la creencia en el temor de las serpientes al hombre desnudo. Los orígenes bíblicos de esta creencia nos remonta al enfrentamiento con la serpiente en el Edén y al simbolismo de la desnudez como representación de la inocencia humana previa al pecado original. ${ }^{6}$ Podemos unir este pasaje, en una misma línea interpretativa, con la imagen de las serpientes como guardianas del infierno, la identificación de la sierpe con el demonio y especialmente su asociación con el pecado de la soberbia. Dentro de este contexto interpretativo queda expuesta más notoriamente la función simbólica de carácter negativo que alcanza la representación de la serpiente.

\footnotetext{
5 Jacques Le Goff, "Lo maravilloso en el Occidente medieval", en Lo maravilloso y lo cotidiano en el occidente medieval, $3^{\circ}$ ed., Barcelona, Gedisa, 1994, pp. 9-24. Referencia en la p. 17.

${ }^{6}$ Ian Michael, The Treatment of Classical Material in the "Libro de Alexandre", Manchester, University Press, 1970. I. Michael menciona la posibilidad de relacionar este episodio con una interpretación tipológica y con la tradición del Physiologus, cfr. pp. 8-9.
} 
Figuraciones simbólicas de la serpiente en el Mester de Clerecía

\section{GONZALO DE BERCEO}

En las cuatro obras de Gonzalo de Berceo que nos ocupan, se comprueba la presencia casi exclusiva de animales reales, en desmedro de la mención de animales fantásticos, pues en la referencia al dragón se anula su carácter imaginario al identificarlo con el diablo. En la concepción cristiana que rige la obra de Berceo, el "draco traydor" (est. 333) que aparece en la Vida de Santo Domingo tiene existencia real o sobrenatural, si se quiere, pero no es producto de la fantasía.

A pesar de esta preponderancia de animales pertenecientes a un entorno fáctico y cotidiano, sin embargo, prima la tendencia a figurar los animales en imágenes que establecen significativas relaciones analógicas y adquieren valor simbólico. Esto no significa la anulación de lo maravilloso ni implica la exclusión de los animales del mundo sobrenatural pues participan en él, ya sea asociados al diablo y a la Virgen o interviniendo en visiones y milagros que constituyen una manifestación propia de lo maravilloso cristiano, se observa la función mediadora de los animales entre el mundo natural de los hombres y el sobrenatural divino, como vehículo que muestra la acción de lo divino en milagros o su proyección en sueños y visiones.

En las hagiografías de Berceo, el animal participa en las pruebas que afronta el personaje y sirven para que se manifieste su santidad. En la Vida de San Millán, aparecen como elementos del mundo hostil en donde el santo lleva su vida de ermitaño. El lugar se describe como inhóspito, habitado por serpientes que "son enojosas, / aven amargos dientes" (45b). El prodigio se muestra en el comportamiento insólito de los animales que acatan la presencia del santo y huyen dejándole el lugar que así queda consagrado como un espacio de lo sobrenatural donde el santo desarrolla su vida de penitencia como eremita (est. 30-33).

En el Poema de Santa Oria, la confirmación de la santidad se da a través de las visiones que experimenta la santa, que es otra forma de proyectarse lo divino en el mundo de los hombres. La visión también es un reconocimiento de las virtudes de la santa por parte de Dios y una advertencia para el resto de los hombres (SO, est. XXVII [24]). En una visión celestial de santa Oria, mediante una expresión figurada se identifica el diablo con la serpiente; así dice de los cardenales: "que sacaron del mundo las serpientes mortales" (XC [87]d).

En la Vida de Santo Domingo encontramos una transformación del diablo en serpiente, en la visión que sufre una novicia también llamada Oria: "Prendie forma de sierpe el traydor prouado" (328a). En cuanto motivo hagiográfico constituye primordialmente un milagro que confirma la virtud de Santo Domingo que vence al demonio, pero además esta aparición puede ser 
interpretada como una prueba para la joven monja (SD, est. 328). A partir de la metamorfosis del diablo en serpiente se establece un paralelo entre la tentación hecha a Oria y el pecado original que cometieron Eva y Adán inducidos por el diablo bajo la misma forma animal (SD, est. 330). Para Alan Deyermond esta asociación constituye otro indicio que marca las connotaciones sexuales de la imagen, pues considera que la visión del diablo bajo la forma de la serpiente puede ser interpretada como una proyección de impulsos sexuales reprimidos. ${ }^{7}$ La interpretación psicológica del crítico inglés se alinea con la lectura de M. A. Diz que, en el milagro del monje borracho, veía los ataques del Demonio encarnado en diferentes animales (can, toro, león) como expresiones metafóricas del mundo de los instintos y a la Virgen y demonios como vestiduras medievales que manifiestan caras diversas de la subjetividad. ${ }^{8}$

En la concepción simbólica del cristianismo, la serpiente como encarnación de lo demoníaco se opone a la paloma que es un símbolo celestial por antonomasia y, en un plano de significación universal, manifiesta el eterno enfrentamiento de las fuerzas del bien y el mal. ${ }^{9}$ Pero que también pueden considerarse proyección de conflictos psíquicos. J. Voisenet observó que detrás de estos animales se revela una conciencia religiosa angustiada y la psicología de toda una sociedad se conforma al modelo clerical, desagarrada entre el impulso al bien y el vértigo del mal: la serpiente y la paloma encarnan estas fuerzas contrarias que dividen al creyente y lo tironean entre infierno $y$ paraíso. ${ }^{10}$

\section{POEMA DE FERNÁN GONZÁLEZ}

En la representación de los animales en el Poema de Fernán González (PFG) se advierte una tendencia a acrecentar su significación simbólica, tendencia que se hace evidente ya en la inclusión de la serpiente en imágenes, comparaciones y metáforas. Al igual que en el Alexandre, aparece en símiles bélicos: "El conde don Fernando, mas brrauo que serpyente" (514a). Con Berceo comparte la metáfora de animal más importante que refiere la asimilación de la serpiente con el diablo. En la primera parte del PFG, el pueblo castellano pide a

\footnotetext{
7 Alan Deyermond, "Berceo, el diablo y los animales", Homenaje al Instituto de Filología y Literaturas Hispánicas "Dr. Amado Alonso" en su cincuentenario 1923-1973, Bs.As., 1975, pp. 82-90, esp. pp. 8790.

8 Marta Ana Diz, Historias de certidumbre: los Milagros de Berceo, Newark, Delaware, Juan de la Cuesta, 1995, esp. Cap.2, pp.69-70.

${ }^{9}$ Cfr. Beryl Rowland, Animal with Human Faces. A Guide to Animal Symbolism, Knoxville, The University of Tennessee Press, 1973.

10 Jacques Voisenet, Bêtes et hommes dans le monde médiéval. Le bestaire des clercs du Ve. au XIIe. siècle, Turnhout, Breposl, 2000, cap. V, pp. 147-190.
} 
Dios la gracia de ser liberados del dominio musulmán mediante una "oración narrativa"11, en la que la serpiente y el dragón aparecen mencionados en los milagros citados que protagonizan personajes bíblicos (106c, 108c, 109d).

La intervención más directa y activa de la serpiente en el ámbito prodigioso se da en un episodio que incluye profecías, visiones y milagros, formas características de lo maravilloso cristiano, y que consiste en la aparición insólita de una serpiente en llamas ante el ejército castellano (est. 465-480).

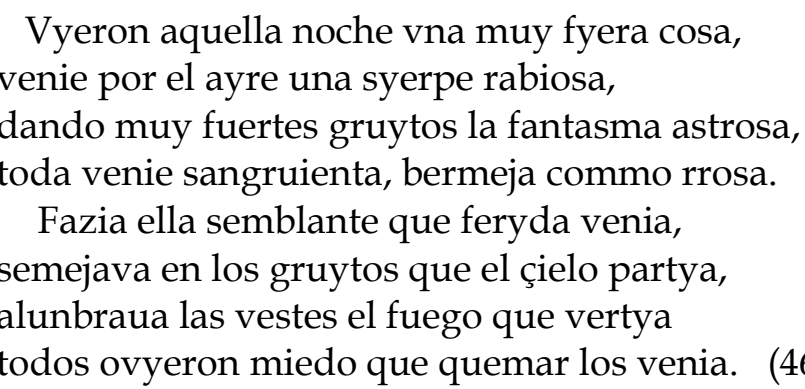

La interpretación de la visión prodigiosa de la serpiente encendida la realiza el conde Fernando que es capaz de identificar el origen demoníaco de la visión y establecer la correlativa función figurativa de la serpiente ("que esta atal fygura diablos la fyzieron", 469c), al mismo tiempo que reconoce su propósito de aterrorizar a los cristianos para ayudar a los moros: "Algún moro astroso que sabe encantar, / fyzo aquel diablo en syerpe figurar" (476 ab). Se produce, en consecuencia, una recuperación simbólica y moralizante de lo maravilloso que atenúa su faceta extraordinaria e imprevisible. En este contexto interpretativo, el animal adquiere una función alegórica y didáctica que se correlaciona con los nuevos argumentos que apelan a la sabiduría y a la fe religiosa de los cristianos para desestimar la portentosa visión. La lectura que el conde Fernando propone de la visión de la serpiente hace que pierda su efecto aterrador y la transforma en presagio propicio a los castellanos pues les muestra el favor de Dios antes de comenzar la batalla.

\footnotetext{
11 Para el tópico de la "oración narrativa", ver: Joaquín Gimeno Casalduero, "Sobre la «oración narrativa» medieval: estructura, origen, supervivencia", en Estructura y diseño de la literatura castellana medieval, Madrid, Porrúa, 1976, pp.11-29. Fernando Baños Vallejos, "Plegarias de héroes y santos. Más datos sobre la oración narrativa", Hispanic Review, 62 (1994), pp.205-215. Alicia Ramadori, "Función de las plegarias en la narrativa española medieval", Cuadernos del Sur. Letras, 30 (2000) pp.47-72.
} 


\section{CONCLUSIÓN}

Si bien cada uno de los textos representa diferentes variantes del mester de clerecía, pudimos observar una similar visión de la serpiente y modos análogos de figuración, que conjugan la apreciación de las características naturales del animal con el énfasis en sus posibilidades simbólicas que responden a la doctrina cristiana. Las imágenes de la serpiente que apelan a analogías con un mundo hostil, en el que prevalece la violencia, la ignorancia y el pecado -ya sea los confines que se desean conquistar, el campo de batalla o el yermo del santo- se basan en una percepción más o menos objetiva de sus características y comportamientos naturales. El animal es elemento integrante de esa realidad que constituye una prueba que el héroe o el santo debe superar. Pero al mismo tiempo, esta percepción se complementa con la visión simbólica propia del cristianismo y adquiere particular relevancia el espacio de lo maravilloso cristiano. La serpiente interviene en acontecimientos sobrenaturales como son las visiones, profecías y milagros, experiencias extraordinarias con las que se identifica el prodigio según la concepción cristiana. En el campo del prodigio también se produce la asimilación simbólica de la serpiente con el diablo, ser sobrenatural pero de activa participación en el plano humano. En síntesis, tanto sea representado en imágenes o interviniendo en prodigios, el animal siempre cumple una función simbólica que responde a principios cristianos. En cuanto figura del mundo demoníaco, la serpiente refleja la lucha universal entre el bien y el mal, manifestación externa y objetiva de conflictos internos entre la aspiración a la virtud y la tendencia al pecado que dividen al ser humano. 